\title{
Study of Clinical Profile of Neonatal Seizures in Level III NICU
}

\author{
P. Anil Kumar ${ }^{\circledR 1}$, V. Ramgopal Rao ${ }^{\circledR 2}$ \\ ${ }^{1}$ Assistant Professor, Department of Pediatrics, Kakatiya Medical College Warangal, Warangal, Telangana, India, ${ }^{2}$ Assistant Professor, Department of Pediatrics, Medi \\ Citi Institute of Medical Sciences, Ghanpur, Telangana, India.
}

\section{Abstract}

Background: During the neonatal age, seizures are the most distinctive sign of neurological disease. Convulsive symptoms are the most prominent forms of neonatal neurological disorders. The goal of this research was to have a better view of the epidemiology, etiology, incidence, forms and mortality of neonatal seizures in our hospital. This research was undertaken to evaluate the prevalence, forms of neonatal seizures, etiology, occurrence period and correlation with etiology, and to establish the mortality correlated with neonatal seizures. For research the etiology and its etiological connection, the occurrence of neonatal seizures. Subjects and Methods: A comprehensive history was collected for the antenatal, natal, postnatal and family history. Age of initiation, form, duration and amount of seizures, consciousness before and after the seizures were taken. Comprehensive neonate examination was performed after detailed history. Relevant investigations were carried out depending upon clinical presentation. Results: In our analysis of 200 neonatal seizures, 194 had one of the four classically identified neonatal seizures. Multifocal clonic seizures were among the most common type of seizures $36 \%$ (72 cases) followed by subtle $27 \%$ (54 cases), GTS $26 \%$ (52 cases), Myoclonic 7\% (15 cases), mixed type of seizures 3\% (6 cases) and focal clonic seizures 1\% ( 2 cases). Conclusion: Because neonatal seizures are most frequently due to birth asphyxia, better antenatal and perinatal care reduces birth asphyxia and if mothers are identified as high-risk. The impact of neonatal seizures is thereby minimized. Subtle seizures are the most frequent form of psychiatric seizure; thus, close monitoring of newborns at risk is important.

Keywords: Neonatal, Asphyxia, Meningitis

Corresponding Author: V. Ramgopal Rao, Assistant Professor, Department of Pediatrics, Medi Citi Institute of Medical Sciences, Ghanpur, Telangana, India.

E-mail: drvramgoparlrao@gmail.com

Received: 27 May 2020

Revised: 29 July 2020

Accepted: 09 August 2020

Published: 28 December 2020

\section{Introduction}

The seizure is characterized as an unexpected paroxysmal disruption in brain activity. It can occur as an inability or lack of control, impaired muscle movement, mental abnormality, sensory disorder, or autonomic dysfunction. ${ }^{[1]}$ Any irregular, repeated, and stereotypic activity in neonates should be regarded as potential seizures. Naturally, neonatal seizures occur in babies during the first 4 weeks of infancy, ${ }^{[2]}$ and are more severe in the first 10 days of development, up to 44 weeks after childbirth. ${ }^{[3]}$ Neonatal epilepsy is a severe neurologic condition with an incidence of 0.95 to $3.5 / 1000$ live births. ${ }^{[4]}$ At this moment, seizures are more common than in any other era of life. The incidence in newborn babies below 1,500 grams and just 2,8 grams for children between 2500 and 3999 grams with a birth weight of only 57,5 per $1000 .^{[5-7]}$ Neonatal seizures are the most distinctive symptom of neurological disorder in newborn age. The convulsive disorder is clinically important because only a few are idiopathic. Neonatal seizures often vary greatly from seizures seen in older children, primarily because the developing brain is less able to disperse widespread or coordinated electrical discharges. ${ }^{[8]}$ This is important to understand neonatal seizures in order to assess their etiology and to manage them for the following three key factors:

1. Seizures are typically linked to severe disease, often require specific treatment.

2. Neonatal seizures can interfere with important therapies such as diet and aided respiration.

3. Experimental data give the reason for concern that seizures per se can trigger brain injury. ${ }^{[9]}$

Seizures come in a number of symptoms, such as universal tonic, multifocal clonic and intermittent movement. This is also necessary to identify them and handle them because delays in identification and diagnosis may contribute to brain injury. ${ }^{[10]}$ The occurrence of epilepsy is not a cause, but 
rather a sign of central nervous system underlying dysfunction related to neurological or metabolic disorders. Among the numerous etiologies, birth asphyxia, neonatal meningitis and metabolic disorders are the most severe neonatal seizure etiologies. Metabolic disorders arise either as an intrinsic cause or a related abnormality.

Early identification and diagnosis of these etiologies are important for maximum control and a successful outcome. Therefore, we plan to study the clinical profile of neonatal seizures, which will assist with early diagnosis and improved prognosis.

\section{Subjects and Methods}

Source of Data: The present study was conducted in the NICU of Gandhi hospital, Secunderabad.

Method of Collection of Data (Including Sampling Procedures if any):

- A patient-based retrospective empirical research was performed at NICU Gandhi College, Secunderabad.

- A total of 200 neonates with seizures consistent with the inclusion requirements were included in the analysis from January 2017 to June 2018, with written and informed consent.

\section{Inclusion Criteria}

All neonates with Seizures were admitted to NICU of Gandhi hospital, Secunderabad.

\section{Exclusion Criteria}

- Isolated minor symptoms such as Apnea or Paroxysmal autonomic shifts (only slight motor periods or apnea without tachycardia) should be omitted from the analysis.

- Neonates with isolated Jitteriness

Detailed antenatal, natal and postnatal background and family background have been documented. Age of onset, form, period and amount of seizures, sensitivity during and between seizures. After an adequate history, a thorough review of neonates was carried out.

Relevant investigations were carried out depending upon clinical presentation

- Complete blood count

- Sepsis screening (TLC, ANC, immature to total neutrophil ratio, CRP)

- Blood glucose: Hypoglycemia is defined as RBS $<40 \mathrm{mg} / \mathrm{dl}$.

- Serum Electrolytes:

- Serum electrolytes were done by colorimetric method.

- Hyponatremia- Serum sodium $<120 \mathrm{mEq} / \mathrm{L}$ and

- Hypernatremia - serum sodium $>150 \mathrm{mEq} / \mathrm{L}$.
- Hypokalemia -serum potassium $<3.5 \mathrm{mEq} / \mathrm{L}$ and

- Hyperkalemia - serum potassium $>5.5 \mathrm{mEq} / \mathrm{L}$.

Total and ionized serum calcium levels (colorimetric method)

- Hypocalcemia- Total serum calcium $<7 \mathrm{mg} / \mathrm{dl}$ (preterm) $\&<8 \mathrm{mg} / \mathrm{dl}$ (term) or ionized calcium $<4 \mathrm{mg} / \mathrm{dl}$ or $1 \mathrm{mmol} / \mathrm{L}$ (preterm) $\&<4.4 \mathrm{mg} / \mathrm{dl}$ or $1.1 \mathrm{mmol} / \mathrm{L}$ (term).

- Hypercalcemia - Total serum calcium $>11 \mathrm{mg} / \mathrm{dl}$ or ionized calcium $>1.45 \mathrm{mmol} / \mathrm{L}$.

Serum phosphorus:

- Hyphosphatemia- serum phosphorus $<3.5 \mathrm{mg} / \mathrm{dl}$.

- Hyperphosphatemia-serum phosphorus $>8 \mathrm{mg} / \mathrm{dl}$.

Serum magnesium:

- Hypomagnesemia- serum magnesium $<1.5 \mathrm{mg} / \mathrm{dl}$.

- Hypermagnesemia - serum magnesium $>3 \mathrm{mg} / \mathrm{dl}$.

- Other metabolic screening includes serum ammonia, serum lactate, urine ketones and urine for reducing substance if metabolic disorders are suspected.

- CSF analysis- Lumbar puncture is considered in all cases with suspected meningitis or septicemia. CSF is analyzed for color, turbidity, glucose, proteins, chloride, and number of cells, cell type and culture.

- Neurosonogram- Neurosonogram is done in all neonates with seizures to rule out intraventricular/ parenchymal hemorrhage, congenital anomalies of the brain.

- EEG- EEG is done in all neonates requiring anti-convulsant therapy.

- CT scan and MRI Brain - CT scan or MRI Brain is done as and when necessary.

\section{Results}

In our sample, 118 (59 percent) were male infants and 82 (41 percent) were female infants with a male-to-female ratio of $1.43: 1$. In the present research, $140(70 \%)$ of the 200 babies were preterm, $60(30 \%)$ were preterm. In the present sample of the 200 cases, 119 (59.5 percent) were Inborn and 81 (40.5 percent) were Outborn. The majority of neonates in this sample were delivered by regular vaginal birth in 121 (60.5 percent) situations. The Caesarean section was performed in 79 (39.5 percent) cases. In our sample of 200 with neonatal epilepsy, < $1.5 \mathrm{~kg}$ was 7 percent, $1.5-2.49 \mathrm{~kg}$ was 46.5 percent and $\geq 2.5$ $\mathrm{kg}$ was 46.5 percent.

Throughout the latest 6-hour seizure initiation analysis 68 cases (34 percent), 6-12 hours 16 cases ( 8 percent), 12-24 hours 01 event $(0.5$ percent) gross first-day seizures were 50 percent (100 cases), on the second day 35 (17.5 percent) neonates were seizures, and on the third day of existence 
Table 1: Distribution of Neonatal Seizures According to Gender, Gestational Age, Place and Type of Delivery and Birth Weight

\begin{tabular}{|lll|}
\hline Sex & No of cases & Percentage \\
\hline Male & 118 & $59 \%$ \\
\hline Female & 82 & $41 \%$ \\
\hline Total & 200 & $100 \%$ \\
\hline $\begin{array}{l}\text { Gestational } \\
\text { age }\end{array}$ & & \\
\hline Term & 140 & $70 \%$ \\
\hline Preterm & 60 & $30 \%$ \\
\hline $\begin{array}{l}\text { Gestational } \\
\text { age }\end{array}$ & No of cases & Percentage \\
\hline $\begin{array}{l}\text { Place } \\
\text { delivery }\end{array}$ & & \\
\hline $\begin{array}{l}\text { Inborn } \\
\text { Outborn }\end{array}$ & 119 & \\
\hline $\begin{array}{l}\text { Type } \\
\text { delivery }\end{array}$ & 81 & $59.5 \%$ \\
\hline $\begin{array}{l}\text { Normal } \\
\text { vaginal } \\
\text { delivery }\end{array}$ & 121 & $40.5 \%$ \\
\hline $\begin{array}{l}\text { Cesarean } \\
\text { section }\end{array}$ & 79 & \\
\hline $\begin{array}{l}\text { Birth } \\
\text { Weight } \\
\text { (Kg) }\end{array}$ & & $60.5 \%$ \\
\hline$<1.5$ & 14 & \\
\hline $\begin{array}{l}1.5-2.49 \\
\geq 2.5\end{array}$ & 93 & $39.5 \%$ \\
\hline
\end{tabular}

21 neonates (10.5 percent) had seizures. The first three days in development combined accounted for $78 \%$ of neonatal seizures. In the present analysis, 100 cases were seizures on the first day, 35 cases were seizures on the second day, 21 cases were seizures on the third day, 34 cases were seizures on the 4th-7th day and 13 cases were seizures between 8 and 28 days. In our analysis of 200 neonatal seizures, 194 had one of the four classically identified neonatal seizures. Multifocal clonic seizures were among the most common type of seizures $36 \%$ ( 72 cases) followed by subtle $27 \%$ ( 54 cases), GTS $26 \%$ (52 cases), Myoclonic 7\% (15 cases), mixed type of seizures $3 \%$ (6 cases) and focal clonic seizures 1\% ( 2 cases).

The most common cause of neonatal seizures is birth asphyxia (47\%) followed by hypoglycemia in $64(32 \%)$ cases, neonatal meningitis in $61(30.5 \%)$ cases, hypocalcemia in $23(11.5 \%)$ cases, congenital anomalies in $14(7 \%)$ cases, hypomagnesemia in $6(3 \%)$ cases and hyponatremia in $04(2 \%)$ cases.
Table 2: Distribution According to Day of Onset, Type, Etiology of Neonatal Seizures

\begin{tabular}{|c|c|c|}
\hline $\begin{array}{l}\text { Days of onset of Neona- } \\
\text { tal seizures }\end{array}$ & No of cases & Percentage \\
\hline$<6$ hours & 68 & $34 \%$ \\
\hline 6-12 hours & 16 & $8 \%$ \\
\hline $12-24$ hours & 01 & $0.5 \%$ \\
\hline First day & 100 & $50 \%$ \\
\hline Second day & 35 & $17.5 \%$ \\
\hline Third day & 21 & $10.5 \%$ \\
\hline Fourth day & 15 & $7.5 \%$ \\
\hline Fifth day & 12 & $6 \%$ \\
\hline Sixth day & 04 & $2 \%$ \\
\hline Seventh-day & 03 & $1.5 \%$ \\
\hline 8 to 28 days & 13 & $5 \%$ \\
\hline $\begin{array}{l}\text { Type of Neonatal } \\
\text { Seizures }\end{array}$ & & \\
\hline Subtle & 54 & $27 \%$ \\
\hline Tonic & 52 & $26 \%$ \\
\hline Myoclonic & 14 & $7 \%$ \\
\hline Multifocal clonic & 72 & $36 \%$ \\
\hline Focal clonic & 02 & $1 \%$ \\
\hline Mixed & 06 & $3 \%$ \\
\hline $\begin{array}{l}\text { Etiology of Neonatal } \\
\text { Seizures }\end{array}$ & No of cases & Percentage* \\
\hline Birth asphyxia & 94 & $47 \%$ \\
\hline Meningitis & 61 & $30.5 \%$ \\
\hline Hypoglycemia & 64 & $32 \%$ \\
\hline Hypocalcemia & 23 & $11.5 \%$ \\
\hline Hypomagnesemia & 06 & $3 \%$ \\
\hline Hyponatremia & 04 & $2 \%$ \\
\hline CNS Anomalies & 14 & $7 \%$ \\
\hline
\end{tabular}

- The onset of seizures on the first three days of life is statistically significant with the etiology of birth asphyxia.

- The onset of seizures on the first day seen in 100 babies, in those 82 babies had birth asphyxia.

- On the second day of life 35 babies developed seizures, 6 babies were due to birth asphyxia, 16 babies were due to meningitis, 17 babies were due to hypoglycemia.

- On the third day of life 21 babies developed seizures, 12 babies were due to hypoglycemia, 9 babies were due to meningitis, 2 babies were due to birth asphyxia.

- On the fourth to the seventh day of life 34 babies developed seizures, meningitis and hypoglycemia were common causes 


\begin{tabular}{|c|c|c|c|c|c|c|c|}
\hline \multirow[t]{2}{*}{ Day of onset of the } & \multicolumn{5}{|l|}{ Etiology } & \multirow[t]{2}{*}{ Total } & \multirow[t]{2}{*}{$\%$} \\
\hline & Birth Asphyxia & Meningitis & Hypoglycemia & Hypocalcemi: & $\begin{array}{l}\text { CNS Anoma- } \\
\text { lies }\end{array}$ & & \\
\hline$<6$ hours & 66 (97\%) & $07(10.3 \%)$ & $09(13.2 \%)$ & $03(4.4 \%)$ & $05(7.3 \%)$ & 68 & $34 \%$ \\
\hline 6-12 hours & $13(81.2 \%)$ & $04(25 \%)$ & $04(25 \%)$ & $02(12.5 \%)$ & $04(25 \%)$ & 16 & $8 \%$ \\
\hline 12-24 hours & - & $01(100 \%)$ & $01(100 \%)$ & $01(100 \%)$ & - & 01 & $0.5 \%$ \\
\hline Day 1 & $82(82 \%)$ & $17(17 \%)$ & $18(18 \%)$ & $09(9 \%)$ & $9(9 \%)$ & 100 & $50 \%$ \\
\hline Day 2 & $06(17.1 \%)$ & $16(45.7 \%)$ & $17(48.6 \%)$ & $09(25.7 \%)$ & $02(5.7 \%)$ & 35 & $17.5 \%$ \\
\hline Day 3 & $02(9.5 \%)$ & $09(42.8 \%)$ & $12(57.1 \%)$ & $03(14.3 \%)$ & $01(4.7 \%)$ & 21 & $10.5 \%$ \\
\hline Day 4 & $02(13.3 \%)$ & $08(53.3 \%)$ & $07(46.7 \%)$ & $02(13.3 \%)$ & $01(6.7 \%)$ & 15 & $7.5 \%$ \\
\hline Day 5 & $02(16.7 \%)$ & $03(25 \%)$ & $05(41.7 \%)$ & - & - & 12 & $6 \%$ \\
\hline Day 6 & - & $02(50 \%)$ & $01(25 \%)$ & - & - & 04 & $2 \%$ \\
\hline Day7 & & 03 & & & & 03 & $1.5 \%$ \\
\hline 8 to 28 days & - & $06(46.1 \%)$ & $04(30.8 \%)$ & - & $01(7.7 \%)$ & 10 & $5 \%$ \\
\hline Total & 94 & 61 & 64 & 23 & 14 & & \\
\hline
\end{tabular}

for neonatal seizures.

- After the first week of life 10 babies have developed seizures, meningitis was a common cause for neonatal seizures.

In the present study, 140 out of 200 cases were the term of which 77 cases developed seizures due to birth asphyxia, 40 cases developed seizures due to hypoglycemia, 39 cases developed seizures due to meningitis, 11 cases developed seizures due to hypocalcemia, 4 cases developed seizures due to hypomagnesemia, 4 cases developed seizures due to hyponatremia and 11 cases developed seizures due to CNS anomalies. Out of 60 preterm babies, 24 cases developed seizures due to hypoglycemia, 22 cases developed seizures due to to meningitis, 17 cases developed seizures due to birth asphyxia, 2 cases developed seizures due to hypomagnesemia and 3 cases developed seizures due to CNS anomalies. Birth asphyxia was statistically significant and more common among term babies and hypocalcemia was slightly more common in preterm babies.

In the present study out of 94 neonates with birth asphyxia, 35 babies had multifocal clonic seizures, 33 babies had a subtle type, and 22 babies had GTS type of seizures. Out of 64 babies with hypoglycemia, 23 babies had multifocal clonic seizures, 21 babies had subtle seizures, and 15 babies had GTS type of seizures. Out of 61 babies with meningitis, 23 babies developed multifocal clonic seizures, 16 babies developed subtle seizures, and 15 babies had GTS type of seizures.

\section{Discussion}

Neonatal seizures are the primary manifestations of the central nervous system. They are never idiopathic, so the central nervous system's teenage reagents to other risks are considered to be non-specific. Neonate attacks are distinct relative to adolescents owing to the immaturity of the nervous system. ${ }^{[11]}$ Even in terms of prognosis and treatment, understanding neonatal seizure etiology is significant. The most prevalent etiology of neonatal seizures is hypoxicischaemic encephalopathy. HIE is also linked with perinatal problems, which may be avoided with adequate antenatal and perinatal treatment. ${ }^{[12]}$ The duration of occurrence of neonatal seizures is substantially linked to etiology (e.g., initiation of seizures during the first three days is strongly correlated with birth asphyxia). Subtle seizures are the most frequent form of seizures that are clinically difficult to detect, so close monitoring of at-risk newborns is required for diagnosis. Seizures are a symptom of CNS disorder due to systemic or metabolic disturbances. Metabolic disorders are commonly transient and rapidly correctable less commonly developed as recurrent causes. They often occur in the neonatal period either as an underlying cause or as an associated abnormality. Throughout the process of their life, seizures are challenging to control because there is a risk of potential brain damage. Prompt detection and treatment of the root cause of seizures are critical for successful management and appropriate long-term results. Neonatal seizures are the major manifestations of the central nervous system. They are rarely idiopathic and are considered as nonspecific responses of the immature central nervous system to different insults the seizures in neonates are different compared to adults because of the immaturity of the nervous system. ${ }^{[13]}$ Recognition of neonatal seizure etiology is often helpful with respect to prognosis and treatment. Hypoxic-ischaemic encephalopathy is the most common etiology for neonatal seizures. HIE is also 


\begin{tabular}{|lllll|}
\hline \multicolumn{2}{l}{ Table 4: Distribution of Etiology According to Gestational Age } & & & \\
\hline Etiology of Neonatal Seizures & Gestational Age & & Total & p-value \\
\hline & Term No. (\%) & PreTerm No. (\%) & & \\
\hline Birth asphyxia & $77(81.9 \%)$ & $17(18.1 \%)$ & 94 & $0.0002^{*}$ \\
\hline Meningitis & $39(63.9 \%)$ & $22(36.1 \%)$ & 61 & 0.1 \\
\hline Hypoglycemia & $40(62.5 \%)$ & $24(37.5 \%)$ & 64 & 0.06 \\
\hline Hypocalcemia & $11(47.8 \%)$ & $12(52.2 \%)$ & 23 & $0.01^{*}$ \\
\hline Hypomagnesemia & $04(66.7 \%)$ & $02(33.3 \%)$ & 06 & 0.4 \\
\hline Hyponatremia & $04(100 \%)$ & - & 04 & 0.2 \\
CNS Anomalies & $11(78.6 \%)$ & $03(21.4 \%)$ & 14 & 0.2 \\
\hline
\end{tabular}

\begin{tabular}{|c|c|c|c|c|c|c|c|}
\hline \multirow[t]{2}{*}{ Etiology } & \multicolumn{6}{|c|}{ Type of Seizures } & \multirow[t]{2}{*}{ Total } \\
\hline & Subtle & GTS & MC & MFC & FCS & Mixed & \\
\hline Birth Asphyxia & $33(35 \%)$ & $22(23 \%)$ & $04(4 \%)$ & $35(37 \%)$ & - & - & 94 \\
\hline Meningitis & $16(26 \%)$ & $15(25 \%)$ & $05(8 \%)$ & $23(38 \%)$ & - & $02(3 \%)$ & 61 \\
\hline Hypoglycemia & $21(33 \%)$ & $15(23 \%)$ & $04(6 \%)$ & $23(36 \%)$ & - & $01(1.5 \%)$ & 64 \\
\hline Hypocalcemia & $07(30 \%)$ & $08(35 \%)$ & $08(35 \%)$ & - & - & - & 23 \\
\hline CNS anomalies & $05(35 \%)$ & $04(28 \%)$ & - & $03(21 \%)$ & - & $02(14 \%)$ & 14 \\
\hline
\end{tabular}

frequently associated with perinatal complications that can be prevented by adequate antenatal and perinatal therapy. ${ }^{[14]}$ The time of onset of neonatal seizures is significantly associated with etiology (e.g., the onset of seizures during the first three days is significantly associated with birth asphyxia). Neonatal seizures occur more commonly in male babies with a male to female ratio of $1.43: 1$. Neonatal seizures were more common in term babies (70\%) with AGA $66.4 \%$ and SGA $33.6 \%$. Neonatal seizures were common in unborn babies, with an inborn to an out-born ratio of 1.46:1. Most of the neonatal seizures occurred in babies delivered by normal vaginal delivery $(60.5 \%)$. Most of the neonatal seizures occurred in babies with a birth weight of more than 1.5 $\mathrm{kg}(93 \%)$. Most neonatal seizures occurred during the first 3 days of life, i.e. $78 \%$. Most of them occurred on the first day of life $(50 \%)$. Birth asphyxia was the cause of neonatal seizures in $82 \%$ of neonates who developed seizures on day-1 of life. The onset of seizures on the $1^{\text {st }}$ three days of life is a statistically significant correlation with the etiology of birth asphyxia. The most common type of seizures was multifocal clonic (36\%) followed by subtle $(27 \%)$, tonic $(26 \%)$, myoclonic $(7 \%)$, and mixed types of seizures seen (3\%). Birth asphyxia was the commonest cause of neonatal seizures (47\%), followed by hypoglycemia (32\%), meningitis (30.5\%). Birth asphyxia and septicemia/meningitis were common causes of neonatal Seizures in our study (38\% each) followed by only metabolic disturbances $19 \%$. In neonatal seizures due to birth asphyxia, $37.2 \%$ had multifocal clonic seizures, $35.1 \%$ had subtle seizures, and $23.4 \%$ had GTS. In hypoglycemic seizures $35.9 \%$ had multifocal clonic seizures, $32.8 \%$ had subtle seizures. In neonatal meningitis, $37.7 \%$ of babies had multifocal clonic seizures, $34.4 \%$ had subtle seizures. Subtle seizures are the most prevalent type of seizures that are clinically difficult to diagnose, so careful observation of at-risk neonates is critical for diagnosis. Seizures are a symptom of CNS impairment that can be triggered by cognitive or physiological abnormalities. Metabolic disorders are normally sporadic and may be quickly reversed or less commonly developed as recurrent causes. We often occur in the neonatal period either as an underlying cause or as an associated abnormality. Hallucinations are challenging to handle throughout their life, so there is a risk of potential brain damage. Early identification and diagnosis of the root cause of seizures are important for effective control and a successful long-term outcome. Seizures related to birth asphyxia produce seizures in the first 24 hours of life. The bulk of hypoglycaemic seizures arise between the first and second days of life. Hallucinations attributed to neonatal meningitis include hallucinations towards the end of the first week of diagnosis. Birth asphyxia has a variety of contributing factors, such as extended second-stage labor and MSAF, typically observed in term babies. In addition, the detection of neonatal seizure etiology is also effective in terms of diagnosis and improved results. 


\section{Conclusion}

Because birth asphyxia is the most prevalent cause of neonatal seizures, an improvement in antenatal diagnosis and early identification of high-risk mothers will decrease the occurrence of birth asphyxia and mitigate the rate of neonatal seizures. Subtle seizures are the most prevalent form of clinical seizures that are difficult to detect, hence close monitoring of at-risk neonates is required. Subtle seizures are the most frequent form of epilepsy, and paramedical personnel and mothers will be sensitized to recognize subtle seizures.

\section{References}

1. Haslam R. Seizures in childhood. In Behrman RE, Kleigman RD. 1668;p. 1686-99.

2. Singh M. Neurological disorders. In the textbook of care of the newborn. New Delhi: Sagar publication. 1999;p. 340-344.

3. Vigevano F. Benign familial infantile seizures; 2005. Available from: https://dx.doi.org/10.1016/j.braindev.2003.12.012.

4. M A. Bergin Neonatal Seizures John P Cloherty Manual of Neonatal Care. 2012;56:729-742.

5. Lanska MJ, Lanska DJ. Neonatal seizures in the United States: Results of the National Hospital Discharge Survey. Neuroepidemiology. 1980;15:117-125.

6. Lanska MJ, Lanska DJ, Baumann RJ, Kryscio RJ. A population-based study of neonatal seizures in Fayette County, Kentucky. Neurology. 1995;45(4):724-732. Available from: https://dx.doi.org/10.1212/wnl.45.4.724.

7. Ronen GM, Penney S, Andrews W. The epidemiology of clinical neonatal seizures in Newfoundland: A populationbased study. J Pediatr. 1999;134(1):71-75. Available from: https://dx.doi.org/10.1016/s0022-3476(99)70374-4.
8. Holmes GL, Khazipov R, Ben-Ari Y. New concepts in neonatal seizures. Neuroreport. 2002;13(1):A3-A8. Available from: https://dx.doi.org/10.1097/00001756-200201210-00002.

9. Nawab T, Lakshmipathy N. Clinical profile of neonatal seizures with special reference to biochemical abnormalities. Int $\mathrm{J}$ Contemp Pediatr. 2016;3(1):183-188. Available from: https: //dx.doi.org/10.18203/2349-3291.ijcp20160156.

10. Levene M. The clinical conundrum of neonatal seizures. Arch Dis Child Fetal Neonatal Ed. 2002;86(2):75F-77. Available from: https://dx.doi.org/10.1136/fn.86.2.f75.

11. Chapman KE, Raol YH, Brooks-Kayal A. Neonatal seizures: controversies and challenges in translating new therapies from the lab to the isolette. Eur J Neurosci. 2012;35(12):1857-1865. Available from: https://dx.doi.org/10.1111/j.1460-9568.2012. 08140.x

12. Zupanc ML. Neonatal seizures; 2004. Available from: https: //dx.doi.org/10.1016/j.pcl.2004.03.002.

13. Volpe JJ. Neonatal seizures. Neurology of the Newborn; 2001.

14. Silverstein FS, Jensen FE. Neonatal seizures. Ann Neurol. 2007;62(2):112-120. Available from: https://dx.doi.org/10 1002/ana.21167.

Copyright: (C) the author(s), 2020. It is an open-access article distributed under the terms of the Creative Commons Attribution License (CC BY 4.0), which permits authors to retain ownership of the copyright for their content, and allow anyone to download, reuse, reprint, modify, distribute and/or copy the content as long as the original authors and source are cited.

How to cite this article: Kumar PA, Rao VR. Study of Clinical Profile of Neonatal Seizures in Level III NICU. Asian J. Clin. Pediatr. Neonatol. 2020;8(4):30-35.

DOI: dx.doi.org/10.47009/ajcpn.2020.8.4.7

Source of Support: Nil, Conflict of Interest: None declared. 